\title{
Autologous Fat Transplantation - A Paradigm Shift in Breast Reconstruction
}

\author{
Daniel Del Vecchio ${ }^{1}$ and Hetal Fichadia ${ }^{2}$ \\ ${ }^{1}$ Back Bay Plastic Surgery and Massachusetts General Hospital, Boston MA, \\ ${ }^{2}$ St. Elizabeth's Medical Center, Tufts University, Boston MA,
}

USA

\section{Introduction}

Fat grafting to the breast is not a new concept. It has been under consideration since the $19^{\text {th }}$ century when pioneers attempted inserting bulk volumes of fat (Neuber, 1893, Czerny 1895). Interest in fat grafting was rekindled with the introduction of liposuction, which provided an easy and reliable source of fat. After a brief pause in evolution of breast fat grafting due to concerns over confounding radiologic findings, and risk of carcinogenesis, fat grafting is once again at the forefront of cosmetic and reconstructive breast surgery as these concerns are have become more manageable. The plastic surgery community has re-assessed its position and has called for further clinical and basic science research in this versatile technique. As discussed below, fat grafting is becoming an invaluable tool for breast reconstruction both for core reconstruction and as an ancillary technique after various procedures for breast reconstruction.

\section{History}

Given the aesthetic importance of preservation of the breast mound and easy availability of adipose tissue, it is only natural that the early beginnings of breast reconstruction and fat grafting are interlinked. Vincent Czerny, a German physician first described breast reconstruction by fat transfer (Czerny, 1895). This was not only a first breast reconstruction, but also one of the initial few attempts at autologous fat transfer (Neuber, 1893). Describing the case of a 41-year-old singer who required unilateral mastectomy for chronic interstitial mastitis and fibroadenoma, Czerny wrote:

"Since both breasts were very well developed, an unpleasant asymmetry, which would have resulted after removal of one breast, would have been a particular hindrance to her stage activity. Luckily the lady had a lipoma, larger than a fist in the right lumbar region. I decided, therefore, to use this for a reconstruction of the extirpated breast " (Goldwyn, 1978)

\subsection{History of breast reconstruction}

The history of breast reconstruction must follow the history of breast cancer surgery. As the various techniques for extirpative cancer cure evolved over the past century, the reconstructive strategies had to likewise evolve. Halsted, who was a pioneer in breast cancer 
surgery, discouraged initial attempts at breast reconstruction. His teachings kept breast reconstruction from emerging as an option because he believed it could conceal local recurrence. (Halsted 1894, 1907, McGraw 1980, Losken and Jurkiewicz 2002). Therefore, many of the initial attempts at breast reconstruction took place in Europe. Ombredanne in France is credited with using the first muscle flap (a reflected pectoralis minor) to create a breast mound, whereas Tansini is credited with using a latissimus dorsi myocutaneous flap (Losken and Jurkiewicz, 2002). In the pre-antibiotic era, the use of prosthetic materials like polyvinyl sponges resulted in high complication rates (DeCholnoky, 1963).

In the post antibiotic era following World War II, the introduction of prosthetic materials like silicone implants ushered in a new era in breast reconstruction (Cronin and Gerow, 1963), and these received a wider acceptance after use of tissue expansion as an initial step after mastectomy (Radovan, 1982). Around the same time, with a better understanding of the vascular supply to the skin, microvascular techniques were developed and this resulted in re-introduction of the latissimus dorsi muscle flap for breast reconstruction (Schneider et al, 1977). This became a workhorse flap for a brief period of time, but had shortcomings like inadequate bulk of the muscle, often necessitating an underlying implant to fully reconstruct the breast volume. In addition, the donor site scar left on the back was significant. In 1982, Carl Hartrampf introduced the transverse rectus myocutaneous flap "TRAM" flap (Hartrampf, 1982). The TRAM flap with its many modifications is one of the most popular methods of autologous breast reconstruction today. Its donor site has an abdominoplasty scar, and there is often adequate soft tissue in the flap to reconstruct most defects. A major disadvantage of this flap is the sacrifice of the rectus muscle, which often results in donor site deformities such as muscle weakness, and abdominal wall hernias.

With further development of microsurgical techniques, perforator flaps became popular in the 1990s with development of DIEP and SGAP. Such flaps use the subcutaneous fat and skin of the TRAM flap, but obviate the need for the rectus to be harvested as the vascular pedicle. This procedure demands expertise in microsurgical techniques and is time consuming, requiring meticulous dissection of the donor vessels, and still leaves a donor site scar.

\subsection{History of breast fat grafting}

With the advent of liposuction in the 1980s, large amounts of unwanted fat could be removed from different body areas using small access incisions and a suction cannula. In this setting, fat grafting was re-introduced in the early '80s, pioneered by Mel Bircoll, who first described a series of fat transplantation for breast augmentation and reconstruction (Bircoll, 1987). Bircoll's contribution to fat grafting, albeit impressive, was met with a considerable amount of criticism from the plastic surgery leadership, with the American Society of Plastic Surgeons ("ASPS") releasing a position statement about the procedure in 1987. Plastic surgeons were essentially banned from attempting this technique (Snyderman, 1987). With all the concerns regarding the unknown risks of carcinogenesis and radiologic changes with fat grafting, the procedure was never adopted and fell into obscurity.

Some Europeans, undeterred by the American position, persisted and continued to push for the technique, though not for cosmetic augmentation. Emmanuel Delay in Lyon, France had begun using fat grafting to the breast for reconstruction as early as 2000 (Delay, 2009) and 
Gino Rigotti in Verona, Italy also had a large series that he presented at the European of Aesthetic Plastic Surgeons in 2007 (Rigotti, 2007).

At the 2006 meeting of the American Society for Aesthetic Plastic Surgery (ASAPS), Baker et al., presented a series of 20 patients augmented with a combination of external expansion and fat grafting (Baker, 2006). Using serial breast MRI and 3D volumetric analysis Baker documented a $180 \mathrm{ml}$ augmentation with documented volumetric survival of the grafts. None of the women had difficult-to-interpret findings on the mammogram. At the latest update of this prospective clinical trial, with over 40 women followed up for at least 6 months and for an average of 30 months, there were still no issues with breast imaging or difficult to interpret masses.

In 2007, Coleman published his landmark review of 17 breast augmentation and reconstruction patients who were treated using autologous fat and were followed up with serial photography (Coleman and Saboeiro, 2007). The results were overall successful with maintenance of volume over 7-12 years of follow up. Coleman used serial grafting sessions instead of injecting large volumes in a single session in a pre-expanded recipient breast like Baker et al.

With the growing realization that with optimal technique, fat grafts to the breast have potential to survive long term and that the radiographic arguments behind the ASPSimposed ban were no longer valid many surgeons across the world have started publishing their previously unpublished work (Khouri and Baker, 2002, Rigotti and Marchi, 2007, Gosset et al 2008)

\section{Physiology of volume maintenance in fat transplantation}

The physiology of fat grafting was initially studied scientifically in 1950 by Peer (Peer, 1950), who observed that isogenous fat grafts have a $100 \%$ resorption rate whereas autogenous fat grafts have a $45 \%$ resorption rate. It should be noted that Peer's work preceded liposuction and he was using blocks of adipose tissue that were excised using open surgical techniques. Peer observed that the larger the graft transplanted, up to a point, the better the survival seemed to be. He postulated that there may be a critical element of micro-angiogenesis that occurs and once it does, perfusion could be re-established to the entire block of tissue. Tissue therefore needed to survive prior to this angiogenesis event, or the entire block would undergo necrosis. Peer postulated this 'cell-survival theory' to explain his findings, but this work was largely overlooked as the trends in plastic surgery at the time focused on skin and fascial flaps for soft tissue reconstruction.

Based partly on the initial work by Peer, there are two main theories explaining maintenance of volume after adipocytes are transplanted into recipient tissue. The "Diffusion/Angiogenesis" theory postulates that adipocytes survive by oxygen diffusion in the recipient site during the first 7-14 days following grafting, with eventual micro angiogenesis and the formation of a viable blood supply to the grafted cells. In this scenario, the transplanted adipocytes are envisioned as surviving the transplantation event in whole or in part, and constitute the volume maintenance that is observed clinically. Overcrowding or excessive interstitial pressure in the recipient site is thought to interfere with diffusion, which leads to cellular death, apoptosis and loss of graft volume. This accounts for the use of successful small graft volume (18 to $34 \mathrm{cc}$ ) that has been reported in breast reconstruction 
where ancillary fat grafting has been used successfully for breast reconstruction of borderzone contour irregularities (Kanchwala, 2008). Smaller volumes of graft compared with the recipient-site volume capacity potentially result in maintenance of a physiologic interstitial pressure environment and a favorable surface-to-volume ratio of graft to recipient, improving oxygen diffusion in the early days after grafting. Just like in a skin graft, early trauma or shearing of the graft-recipient interface is thought to damage micro-angiogenesis and decrease graft survival.

A competing theory of graft volume maintenance is based on the experimental work of Morrison who demonstrated adipocyte proliferation and angiogenesis in a perforated hollow tube filled with a non-viable poly (D, L-lactic-co-glycolic acid) ("PLGA") sponge matrix which was implanted in the groin of rats (Dolderer et al, 2007). In the so-called "Morrison" (or better described as the "Scaffold") theory of volume maintenance post fat transplantation, all or most of the transplanted adult adipocytes are destined to die. Rather than survive to maintain volume, these dead cellular elements act as a non-viable matrix or scaffold, through which macrophages penetrate and through which recipient-site stem cellmediated angiogenesis and adipogenesis occurs. Interestingly, Peer's original 1950 "cell survival theory" postulated that human fat grafts disappeared completely a short time after transplantation and noted that "small autogenous multiple grafts had surviving portions that one year after transplantation appeared like normal fat tissue."

Rather than choose between mutually exclusive theories, it is our belief that a third theory exists to explain volume maintenance after fat transplantation. According to the "Tandem" theory, some transplanted adipocytes survive by diffusion and receive a blood supply by eventual micro-angiogenesis, while others do not and act as a scaffold for recipient site cells to enter and remodel. Thus, both mechanisms are working in tandem in any given system.

\section{Not all fat grafting is the same - Definition of mega-volume fat grafting}

Early applications of fat grafting in breast reconstruction involved injection of small amounts of fat for contour correction or filling defects left after breast conservation therapy (Losken et al 2011, Rietjens et al 2011). However, there have been reports of complete breast reconstruction after mastectomy being accomplished by fat grafting with good results (Serra-Renom et al, 2011, Babovic, 2010, Fitoussi et al 2009, Delay et al 2010). The technique of fat grafting used in the face for nasolabial folds is different from the technique of fat grafting used to treat chronic wounds, or to reconstruct radiated mastectomy sites. What is apparent is that not all fat grafting can be lumped into one technique, as not all fat grafting is the same. Sometimes fat is required to only provide volume, whereas in other cases its use is more to supply a regenerative effect, as in the case of a chronic wound (Cervelli et. al, 2009). Therefore, we propose there are at least four separate categories of fat transplantation: high volume vs. low volume, and regenerative vs. non-regenerative, as depicted in Figure 1, below:

We define mega-volume fat grafting as transplantation of over $100 \mathrm{cc}$ of processed fat for core volume projection replacement. In so doing, our technical strategies will cater to the demands of this large volume, mainly non-regenerative case. 


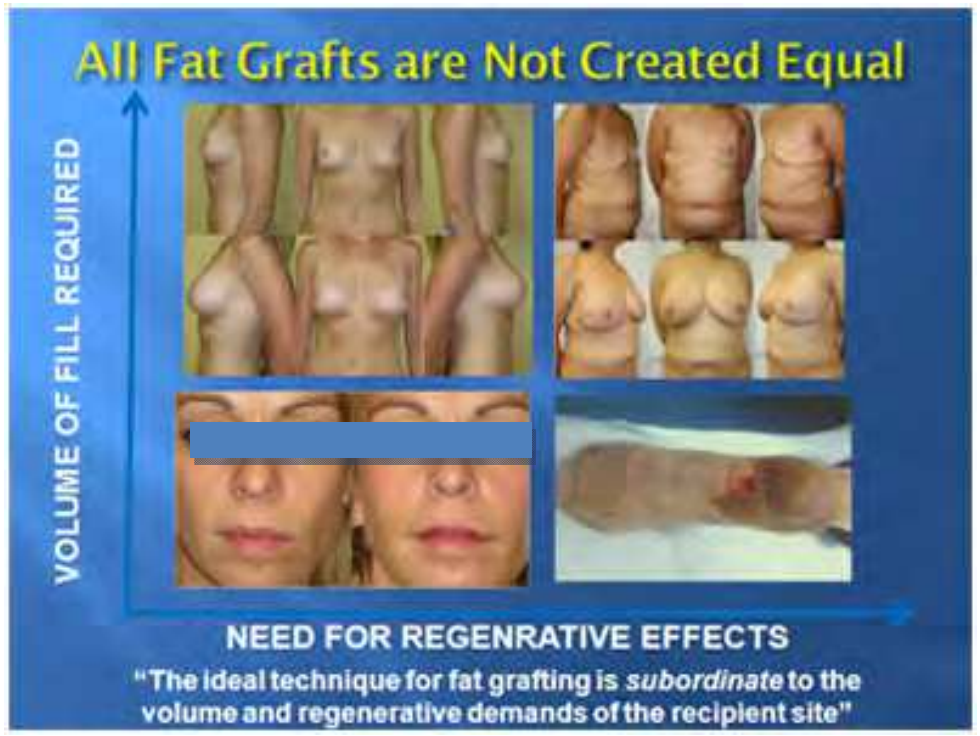

Fig. 1. A Matrix Classification of Fat Grafting. The correct strategy for fat grafting must take into consideration the relative volume capacity and regenerative demands of the recipient site. (Reconstruction case courtesy of Roger Khouri, MD)

\section{From science to the operating room - Surgical variables in fat transplantation}

Four clinical factors appear to have a significant effect on the survival of grafted fat cells:

1. Fat Harvesting

2. Fat Processing

3. Fat Grafting

4. Role of the Recipient Site

\subsection{Fat harvesting}

Cannulas: Diameter and Hole Size: Although it has been reported in a histological study that larger cannula sizes $(6 \mathrm{~mm})$ harvest fat with better viability than with smaller cannulas (Erdim et al, 2009), viability in this report was measured using cell isolation and counting adipocytes with a haemocytometer. Such an experimental endpoint only represents the first step of a multi-stage procedure that must consider all stages, with the clinical endpoint being long-term (six months or greater) volume retention after transplantation into an animal host.

Smaller cannula sizes theoretically create less donor site trauma and allow for removal of smaller sized lobules of fat, which may improve flow characteristics and reduce trauma during re-injection. An important consideration besides cannula size is cannula hole size and number of holes. A 12-gauge cannula with 6-8 side holes $2 \times 1 \mathrm{~mm}$ in size can extract a significant amount of fat despite its small caliber. 


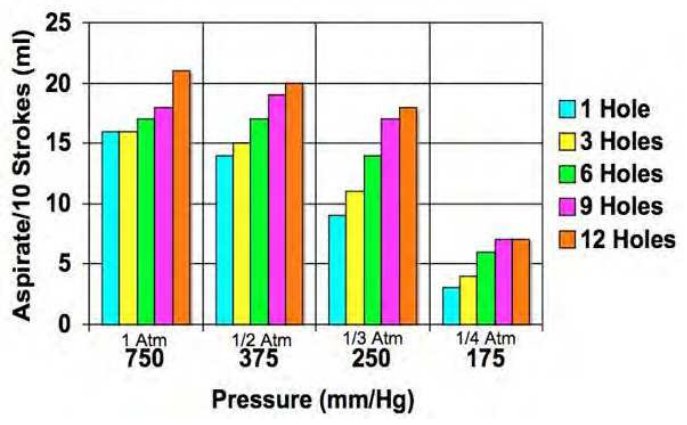

Fig. 2. Varying negative pressure and hole size, the volume of fat flowing through cannulas (measured in cc of fat per 10 strokes) is efficient at 6-12 holes, even at lower negative pressures. (Data: courtesy of Roger Khouri, MD)

The summation of the surface area of the individual openings on a 12 gauge, 12-hole cannula approaches or exceeds the surface area of the opening of a classic $10 \mathrm{~mm}$ one-hole cannula, once used in the 1980s. The result is better tissue flow with less donor area trauma. Further, each hole selects for lobules of uniform small size, which are more likely to flow easily through the injection cannula during the grafting phase of the procedure, without the need for further processing or syringe transfers. The hole sizes on the aspiration cannula approach the size of the hole on the injection cannula, providing "equalization" of hole sizes for more efficient fat flow (see below under fat injecting).

Negative Pressure: The literature regarding the isolated effects of negative pressure suggests that adipocytes can be suctioned below $700 \mathrm{~mm} \mathrm{Hg}$ without undue trauma (Shiffman, et al, 2001). Any claims of syringe suctioning being safer than machine suctioning should be carefully examined. While a standard liposuction machine can generate up to one atmosphere $(760 \mathrm{~mm} \mathrm{Hg})$ of negative pressure, a $60 \mathrm{cc}$ syringe connected to an in-line manometer can also generate nearly one atmosphere of negative pressure (Fig. 3). With regards to the effect of negative pressure on adipocyte viability, it is likely that absolute pressure and not the source of this pressure is the key variable in adipocyte trauma.

Location of Donor Fat: Animal studies have not demonstrated superior donor site fat based on anatomic location (Ullman et al, 2005), and clinically we have not observed anatomic location of the donor fat to be of significance in terms of volume retention. Although reports in the literature (Padoin et al, 2008) suggest the lower abdomen and inner thighs to be richer in the source of stem cells, this study used C-Kit expression as a proxy measurement for stem cells. C-Kit expression also measures lymphocytes and on this basis the conclusions of this paper are in question. In reality, what is more important to consider is the relative abundance and requirements of donor graft in each individual case, and the surgical plan should aim to avoid or minimize donor site deformities. It may turn out that that adipocyte cellular size, which varies in different body regions and also among different patients may be a more important variable than location per se. Larger cells have a higher likelihood of mechanical cell membrane damage during extraction, and it may be this variable of cell size relative to cannula hole-size that is more important than the specific area on the body used for harvest per se. 


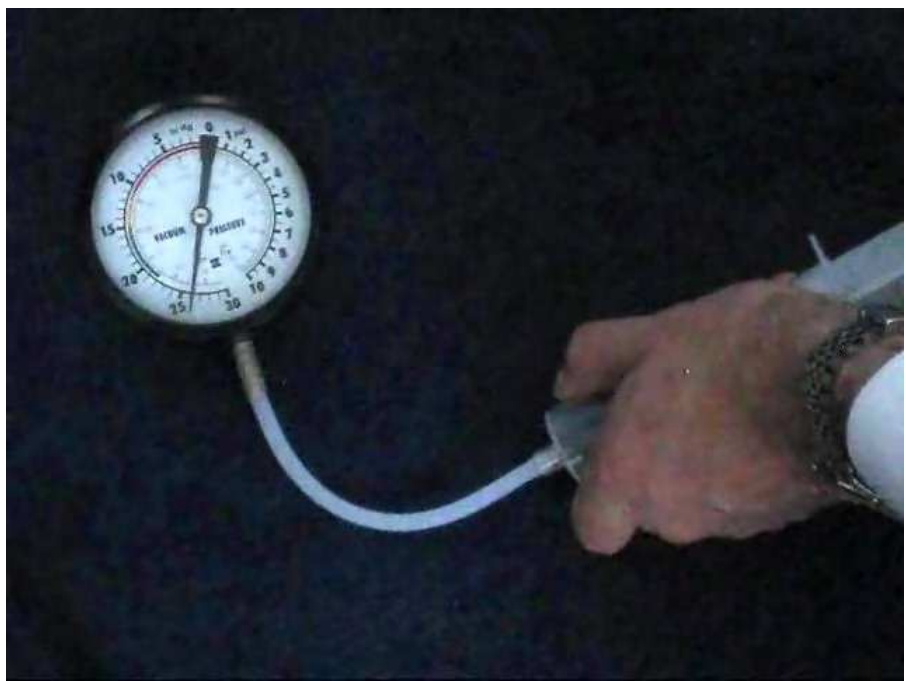

Fig. 3. A 60cc syringe can generate close to one atmosphere $(30 \mathrm{in}=760 \mathrm{~mm} \mathrm{Hg})$ of negative pressure, dispelling the myth that syringe suction is "safer" than machine suction.

Another variable of unknown importance in fat harvesting remains the negative impact of air exposure (Kaufman et al, 2007). Despite its widespread mention, there is a paucity of scientific data quantifying the effect of air exposure on adipocyte viability (Aboudib et al, 1992). Techniques of fat processing range from drying fat on Telfa Rolls (high air exposure), to completely closed systems employing intravenous tubing, three way stopcocks and IV bags for collection.

\subsection{Fat processing}

Peer's cell survival theory of grafted en bloc fat dates back over 50 years and suggests that the number of calls transplanted at the time of transplantation may correlate with the ultimate fat graft survival volume (Peer, 1950). After Ilouz's breakthrough application of liposuction (Ilouz, 1983), fat became available in a fragmented form. The cell survival theory of solid fat transplantation may have influenced the use of high-speed centrifugation as a potential strategy for effective fat grafting. Historically, the penchant for centrifugation may have arisen from the need to graft as much adipocyte biomass as possible into a limited space. Although centrifugation can process highly concentrated fat, there are potential problems associated with it when this technique is employed in megavolume fat grafting:

- The cells may be damaged due high G-forces (Kurita et al, 2008)

- It is a time and labor-consuming process

- High fat concentrations may cause clumping and more difficult flow during re-injection

One of the most confusing metrics in fat grafting is a lack of standardization when one discusses "percent yields". Once fat is lipo-aspirated as donor graft there are an infinite number of different concentrations of adipocyte volume relative to non-adipocyte volume (blood, serum, crystalloid) that can be reached prior to grafting the recipient site. Unless the 
concentration of adipocytes in the grafted material can be accurately measured and unless the process of fat concentration is standardized, one cannot reliably measure the percent of adipocyte volume that survived grafting. In an effort to move toward an acceptable technical standard and to allow for better comparison of volumetric data in clinical series, careful documentation of the following data should be performed in mega-volume fat grafting patients:

- Obtain a baseline mammogram of the breast

- Prior to expansion, objectively document breast volume (MRI, 3D imaging, or both)

- Document the process used for crystalloid separation (decanting, low speed centrifugation, high speed centrifugation)

- Document the volume of processed material grafted in cc

- Objectively document the post graft volume of the breast at 6 months or more (MRI, 3D imaging, or both)

Our strategy in mega-volume fat grafting is based on the concept of minimizing extracorporeal adipocyte time ("EAT"). Whichever theory of fat volume maintenance one believes is true, all should agree that excess time is detrimental for patient safety, cells, and lastly, surgeons. Therefore, we employ the large syringe technique to process $480 \mathrm{cc}$ of fat in 2 minutes, which is the most efficient method of fat dehydration currently available.

\subsection{Fat injecting and shape-modifying techniques}

The selection of an injection cannula used in mega-volume fat grafting follows similar principles to those of harvesting. Small gauge cannulas theoretically reduce trauma to the breast recipient site, which potentially reduces the risks of bleeding, hematoma, and resultant poor graft oxygen diffusion. The hole size of the injection cannula should match closely with the hole sizes of the aspiration cannula. By matching hole sizes, the selected size of the harvested lobules of fat are more likely to flow easily through the injection cannula without blockage or undue resistance (Fig 4).

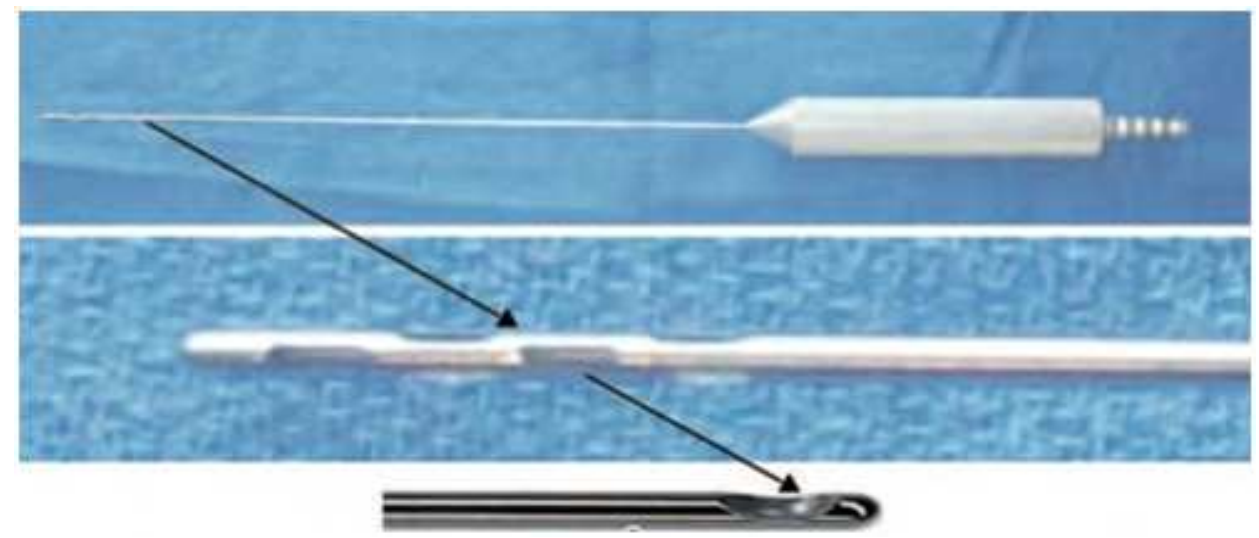

Fig. 4. Equalization of Hole Size. The opening in the $3 \mathrm{~mm}$, 9-hole aspiration cannula (top, center) is nearly equal in size to the hole opening in the 16-gauge blunt tipped side hole injection cannula (bottom), improving tissue flow on injection. 
There are currently two methods of injecting fat in a manner that seeks to increase dispersion and surface to volume contact with the recipient site - the "Mapping" technique and the "Reverse Liposuction" technique. Despite using these different techniques, the authors' independent long-term volume maintenance is essentially the same, each demonstrating an average increase in breast volume of $250 \mathrm{cc}$ on average at six months by quantitative volumetric MRI imaging.

The Mapping Technique: Donor cells have the highest chance of survival with the technique that best ensures an even, three-dimensional dispersion of the fat. The mapping technique involves the use of small ( 3 cc-5 cc) syringes handheld and connected directly to a 16 Gauge blunt curved side-hole cannula. Markings are made in the recipient areas to aid in a systematic, diffuse and even injection of the entire recipient area. 8-10 circum-mammary and 4 circum-areolar entry points are usually made with a $14 \mathrm{G}$ hypodermic needle (Fig. 5). Through each entry point the $15-20 \mathrm{~cm}$ long cannula makes multiple tunnels that fan out radially and injects 1-2 cc of fat only upon axial withdrawal. The cannula is then inserted into another adjacent entry point and the fanning process is repeated to yield a 3-D weave that evenly crisscross and covers the recipient space.

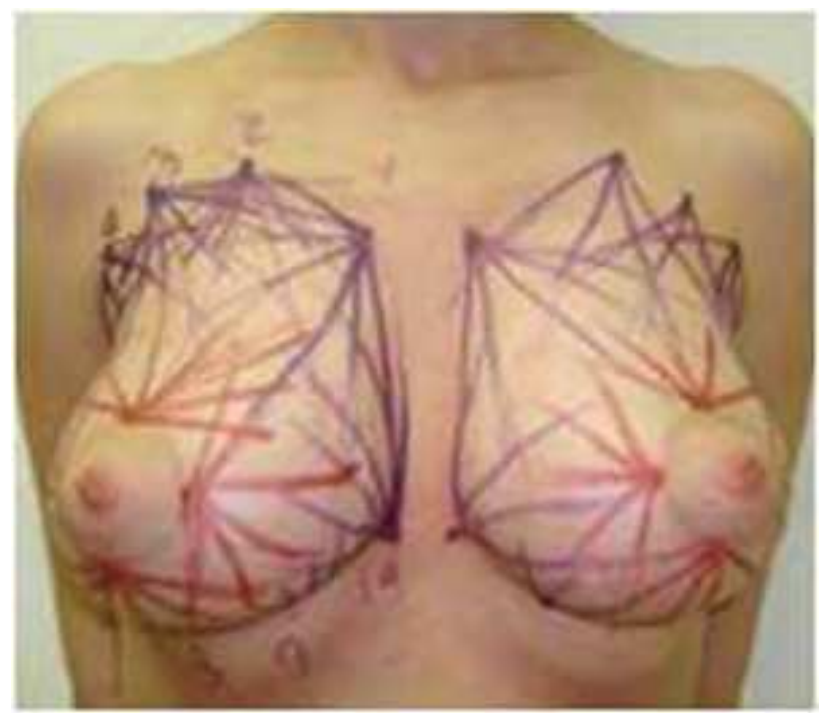

Fig. 5. Markings for the Mapping Technique of Fat Injection. On the breasts, 8-10 circummammary and 4 circum-areolar needle puncture entry sites with radially fanning tunnels from each site provide a well- diversified insertion of the grafts

Multiple levels of graft are deposited, deep from the base of the breast just above the pectoralis fascia, to the subcutaneous space immediately subjacent to the dermis. Direct injection of fat into the dense parenchyma of the breast is never performed. This technique is deliberate and exact but does take time. In addition, it requires the operator to deploy the plunger and withdraw the needle at the same time. Overall, the Mapping technique may be more suitable for surgeons beginning mega-volume fat grafting for breast augmentation because it is more exact and deliberate. For breast reconstruction, it is clearly beneficial, 
especially in scarred areas caused by mastectomy and/or irradiation where a careful and deliberate graft placement is necessary.

The "Reverse Liposuction" Technique: The reverse liposuction technique seeks to evenly disperse the fat into the subcutaneous and non-breast parenchyma in as efficient a manner as is possible. 6-8 needle insertions are made using a 14-gauge needle on the breast, along the infra-mammary fold ("IMF") and spaced $4-5 \mathrm{~cm}$ laterally toward the axilla. Using a straight, $15 \mathrm{~cm}$ blunt side- hole, 16 gauge needle loaded directly onto $60 \mathrm{cc}$ syringes, the fat is injected using a controlled "to and fro" liposuction movement with constant light depression on the plunger. With every pass of the needle the direction is changed slightly to create a fanning pattern of vectors. This is repeated in each different insertion site and at multiple planar levels from the base of the breast. The axillary insertion is also used to place graft in the sub-muscular position and this approach is felt to be the safest method of navigating the sub pectoral space. The rate of graft insertion in this technique should be 1-2 seconds per cc, which results in a 1-2-minute/60 cc of fat rate, or a $300 \mathrm{cc}$ per breast grafting session performed in 10-15 minutes on each breast. The Reverse Liposuction Technique is more time efficient and can be utilized in cases where there is no internal breast scarring, no dense adherence of skin to the chest wall, and where the breast is adequately expanded. Hence, this technique might not be the best technique for breast reconstruction in an irradiated breast. Another potential benefit of the reverse liposuction technique is that $60 \mathrm{cc}$ syringes generate lower maximum pressures than do 5 cc syringes, which generate higher pressure. Therefore, if there is a blockage of flow along the insertion needle due to clumping, this will occur at a lower pressure using a $60 \mathrm{cc}$ syringe, with less potential damage to the grafted cells and less likelihood of pushing the blockage through, creating a bolus.

\subsubsection{Breast shape modification using 3 dimensional ligamentous band release}

Once the fat is grafted, the internal parenchyma is under higher pressure. Contour irregularities due to internal ligamentous tethering can be manifest, especially seen at the interface between the natural infra-mammary fold and the newly augmented breast mound. A technique first described by Rigotti, who employed a pickle fork to release heavily scarred recipient site radiated tissue, is used to release subcutaneous ligaments and scars in breast augmentation and reconstruction with fat grafting. This technique is called three dimensional ligamentous band release, or "Rigottomy". 3D Ligamentous band release is a powerful technique that can change breast shape. This technique, like meshing a twodimensional skin graft, releases contour deformities of the breast parenchyma in three dimensions. Grafted fat immediately fills space created and the fat keeps distance between the transected scar or band, so the scar or band does not reform.

\subsection{The role of the recipient site in fat transplantation}

Negative pressure on the breast prior to fat transplantation creates internal expansion of the breast parenchyma by drawing in more fluid, creating an edema-like state, and by increasing the size and caliber of blood vessels. The authors postulate that non-surgical preoperative expansion of the breast recipient site enhances fat grafting results by five main effects: 
Bigger potential spaces available for overall volume of graft;

Reduces the demand on adipocytes to act as internal expanders, resulting in undue pressure;

Augments tension on internal constrictions and scars, so breast shape can be addressed;

Variables that are time consuming (e.g. centrifugation) become less demanding;

Angiogenesis effect may increase recipient site oxygen tension and lead to better graft take.

The VAC® device has markedly improved outcomes in many types of difficult open wounds by clearance of bacteria and reduction in fluid volume (Saxena et al, 2007). In open wounds, micromechanical forces such as negative pressure elicit tissue deformation forces that stretch individual cells, thereby promoting proliferation in the wound microenvironment. The application of micromechanical forces on cells has been demonstrated as a useful method with which to stimulate wound healing through the promotion of cell division, angiogenesis, and local elaboration of growth factors (Saxena et al, 2004, 2007). The deformational forces of the VAC® device are consistent with this mechanism of action and are similar to the negative pressure exerted on the breast when BRAVA pre-expansion is used. Pre-expansion to the breast may therefore be more than just "increasing space". Negative pressure therapy to the breast may demonstrate similar effects of angiogenesis, cell division, and up-regulation of growth factors in the breast recipient site.

For small graft volumes (100 $\mathrm{ml}$ or less), pre-expansion is not a pre-requisite as much as it is for breast augmentation, as it does not result in high interstitial pressures, as the capacity of the recipient site can receive such a small volume with relative ease.

\section{Surgical technique}

Fat grafting for breast augmentation or reconstruction does not begin with surgery. Proper patient selection and motivation for use of the external expansion device, and finally education as to the unknown potential risks of fat grafting and the need for staged procedures is essential to success. A breast reconstruction from a mastectomy takes 3-4 sessions of fat grafting spaced 4 months apart; if the patient has had radiation the number of sessions is increased to $4-5$. Patients must be counseled prior to initiating the process that tis is a long reconstructive effort in which the patient plays and active (pre-expansion) role.

Following proper patient selection, patients undergo three weeks of pre-operative external expansion using the BRAVA device. The device is worn during awake hours, usually in the evenings after work, as night-time use proves ineffective because the device detaches during sleep. Patients are encouraged to expand 6-8 hours a day and are checked regularly in the office to monitor their progress. The use of 3-D imaging aids in the qualitative measurement of progress or the lack thereof. A 2-3 fold increase in volume of the breast mound or breast is sought prior to grafting (Fig. 6 \& 7).

Preoperatively, the patient is initially marked for areas to be suctioned, and the breasts are marked circumferentially for areas of proposed needle insertions. Any constricted areas are outlined for planned release using a percutaneous needle. Markings are placed at 8-10 proposed sites, circumferentially around the breast. 


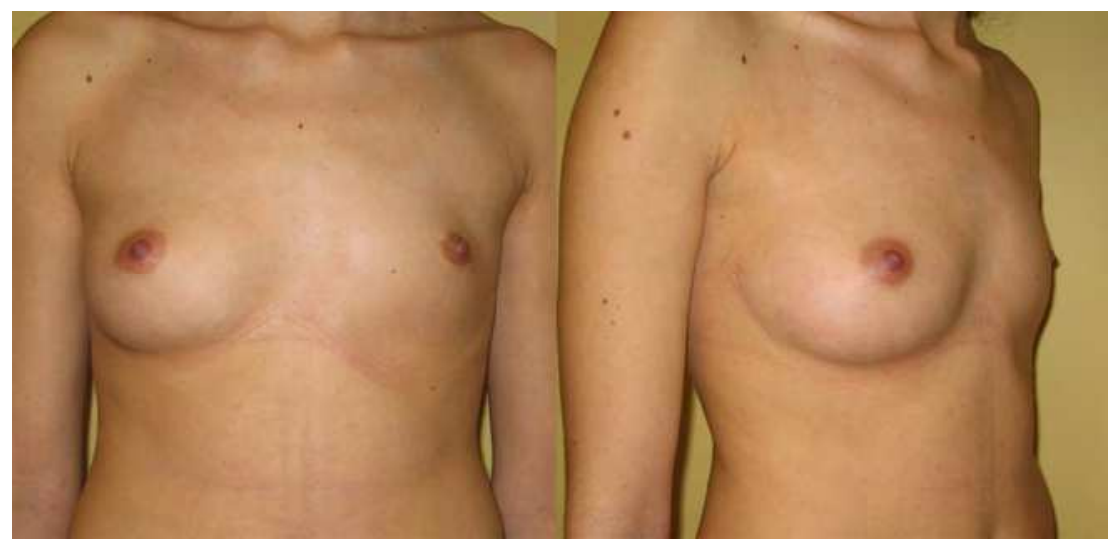

Fig. 6. 18-year-old patient with absence of left breast following tumor excision as an infant. This patient would be a poor candidate for prosthesis, as a breast implant could never match the natural breast on the right. A complex flap like a TRAM would leave a significant donor site deformity, and the patient does not have excess abdominal fat. In addition, she may be considering child bearing making an abdominal muscle closure less attractive. Note the lack of left breast parenchyma and skin, with decreased clavicle to nipple-areolar distance.

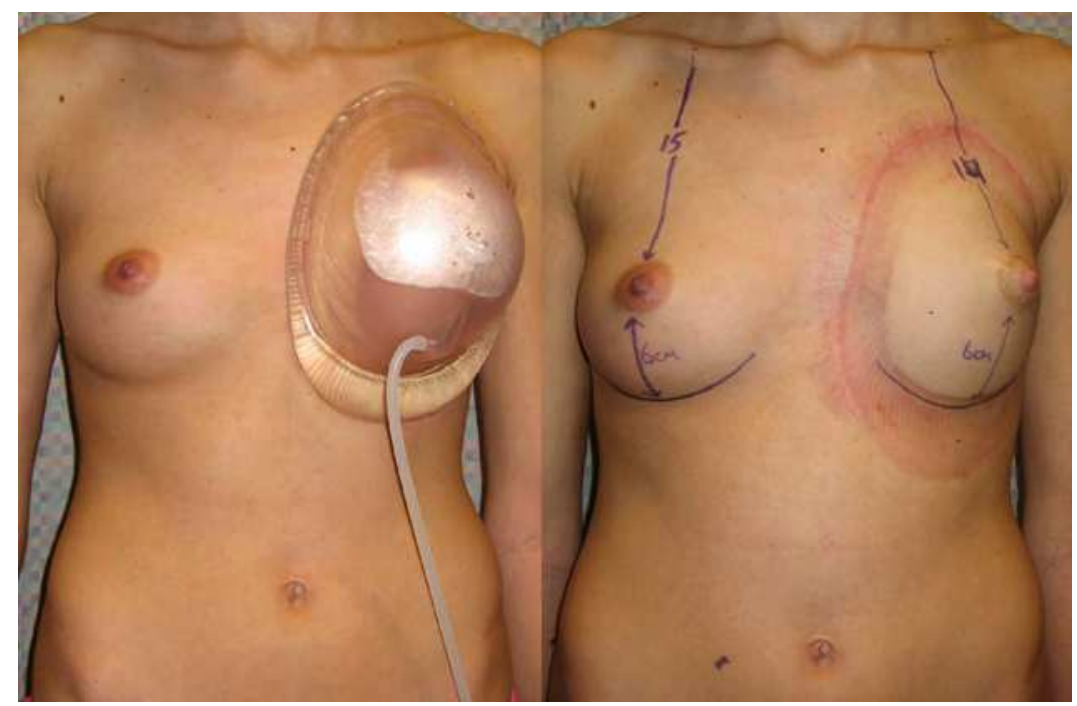

Fig. 7. Preoperative external pre-expansion for reconstruction of the left breast. The patient wore the BRAVA device 6-8 hours a day for three weeks. Note the increased volume, and the increased skin as the left nipple areola complex is almost even with the right.

Liposuction is performed using a 12-gauge multi-hole (9-12 hole) cannula. Smaller cannula sizes lead to less subcutaneous tissue trauma, faster recovery, and smaller fat lobules, which result in better fat flow and less clumping. Multiple holes lead to more efficient and faster fat removal. Our collection technique is as follows: 
Using a sterile "in-line" container, fat is aspirated at 2/3 to $3 / 4$ of an atmosphere (500-600 $\mathrm{mm} \mathrm{Hg}$ ) suction by attaching a sterile clear collection canister to a standard vacuum machine off the sterile field. A $3 \mathrm{~mm} 9$ hole cannula with a wide handle and ribbed connector end is used to attach to the liposuction tubing. Maximal negative machine pressures are avoided when using this technique and vaporization of the fat ("boiling" appearance) in the collection canister is to be avoided at all costs. This technique initially collects the fat into $1200 \mathrm{cc}$ canisters and can be performed with existing equipment used in an operating room (Figure 8).

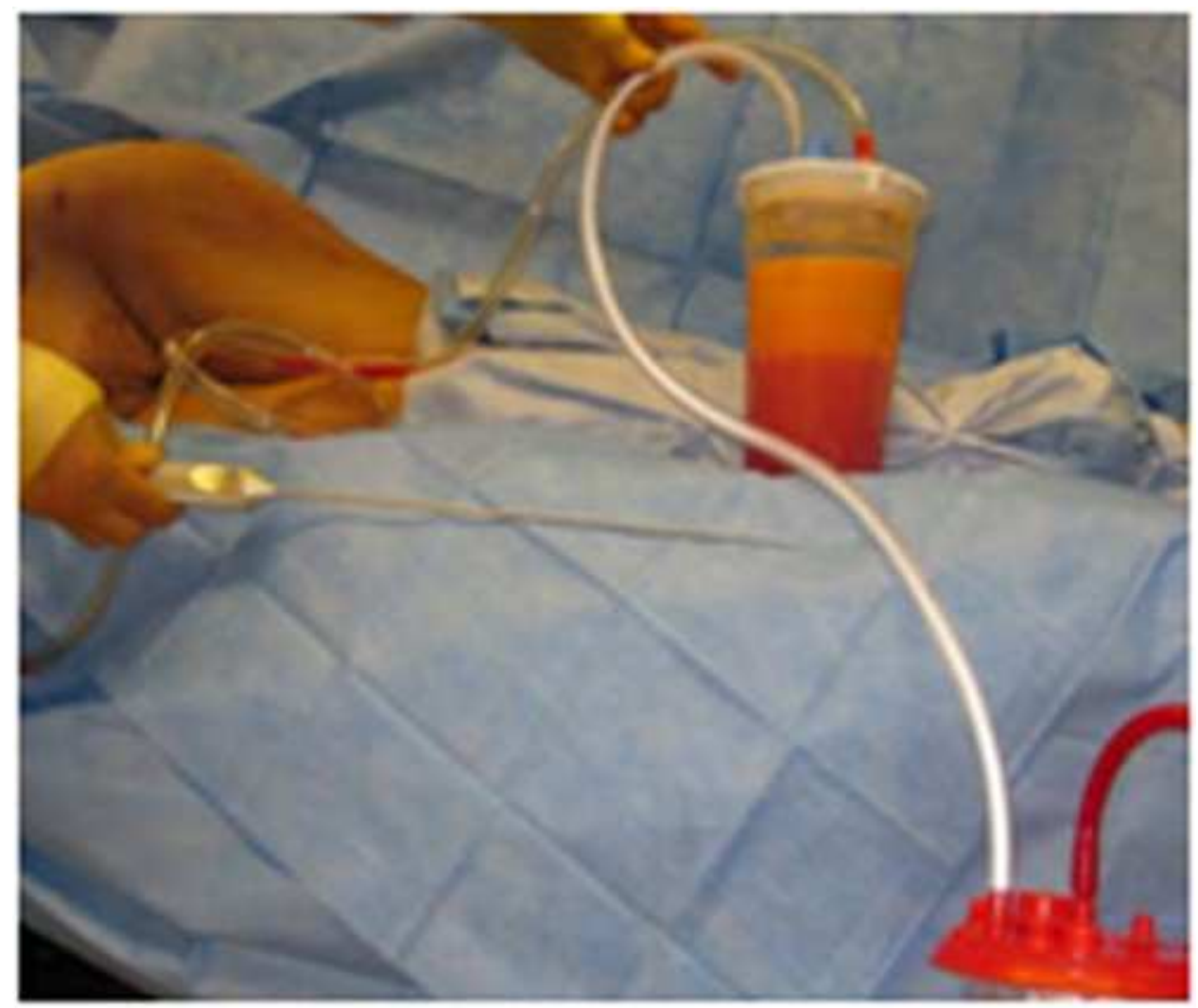

Fig. 8. "In line method" of fat collection in mega volume fat transplantation. A sterile plastic canister on the field collects the fat and is in line with the liposuction machine canister (shown in red). No fat should be lost to the non-sterile canister.

Ideally, fat should be processed so as to separate blood, infiltration fluid, and cell debris from healthy adipocytes with minimal trauma. Once the fat is collected, we use the following method for removing unwanted crystalloid:

"Large Syringe" Method: Several in-line collection canisters are used during the machine liposuction. (Figure 9, a-e). Every time a canister is full, a new canister replaces it. The canisters containing the lipoaspirate (a) are then allowed to stand for 10 minutes allowing 
fat to separate from crystalloid. This fat is then drawn up into $60 \mathrm{cc}$ syringes (b) directly from the collection canister, and placed in a mega volume centrifuge (c). Additional low-G force centrifugation of these 60 cc syringes then removes an additional $20 \%$ crystalloid $(d, e)$.
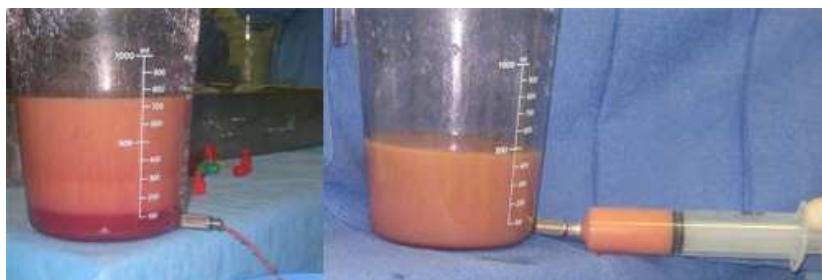

a.

b.
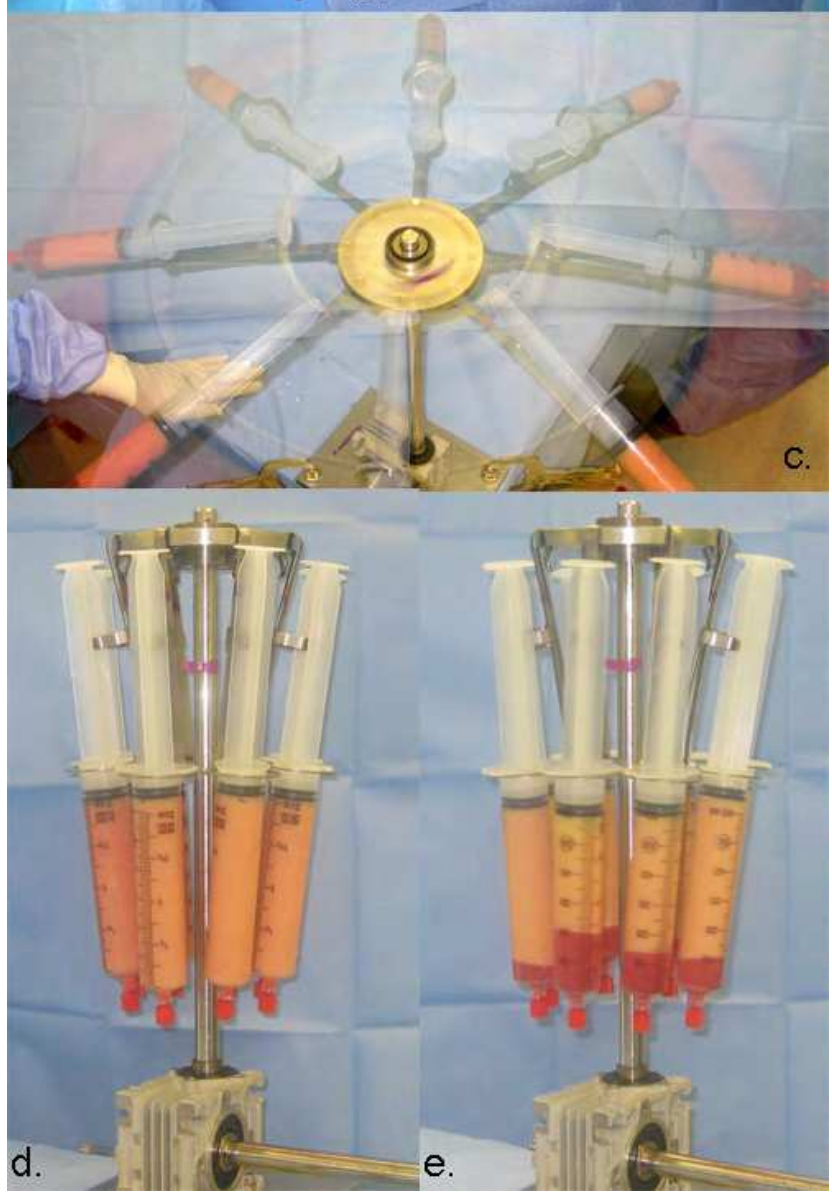

Fig. 9. "Large Syringe" method of fat processing. Fat that appears to be pure fat after decanting at $1 G(a, b)$ actually still has considerable (20\%) amounts of crystalloid, that can be efficiently removed in minutes using a low-G force hand cranked sterile centrifuge (c). Before (d) and after (e) centrifugation, demonstrating the extraction of unwanted fluid and blood. 
If the recipient site has been pre-expanded for complete breast reconstruction, then the emphasis on hyper-concentrated fat, separated at $1300 \mathrm{G}$ is unnecessary. This is because over- expansion of the recipient site affords is the opportunity to inject less concentrated fat. This less concentrated fat is theoretically less traumatized, flows better, disperses better because it is less concentrated, and finally takes less operative time and manpower to process. These are the essential elements of the large syringe technique. We have focused on effective expansion of the recipient site and an efficient timely procedure, and have shifted our focus away from hyper concentrated fat and from "over-correction", because of resultant overcrowding, interstitial hypertension, and volume capacity limitations leading to subsequent fat necrosis.

Once the fat is separated from unwanted crystalloid, injection into the breast begins. Injections are performed using $15 \mathrm{~cm}$ "Coleman" (Mentor Incorporated, Santa Barbara, California) side hole needle. We employ the so-called "Reverse Liposuction" technique (Fig 10). If fat has been harvested and collected using the "In Line" machine and Large Syringe techniques, the fat is already in $60 \mathrm{cc}$ syringes. These syringes are simply loaded onto the Coleman needle and injected into the breast. Multiple insertion holes are employed in a pattern around the breast periphery and in the areas that require volume for symmetry. Insertions along the medial upper quadrant are generally avoided to reduce the possibility of pigmented large needle scars, as this is the part of the breast often seen in low cut clothing. Transplanting fat for augmentation or reconstruction is an iterative process, with surgical artistry and judgment about how much fat and where to inject the fat being based on a continually changing breast as the procedure evolves. Knowing where to graft, when to stop, and how to release bands to effect shape change become the knowledge and skill of the fat grafting surgeon.

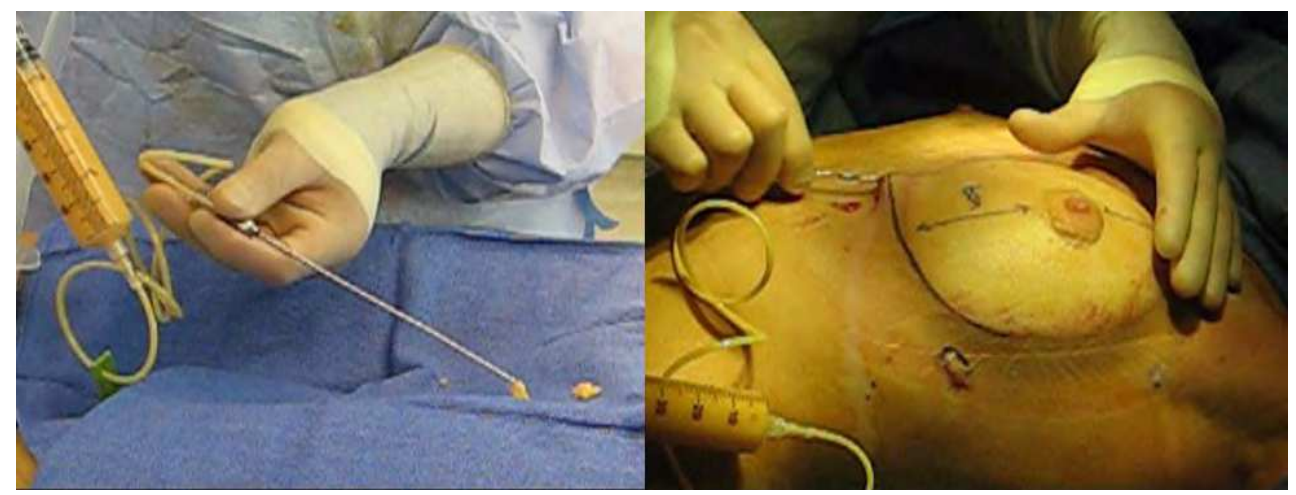

Fig. 10. Reverse liposuction technique used in breast fat transplantation. (Left) In this setup, an assistant applies syringe pressure via connected intravenous extension tubing. An alternative is for the surgeon to hold the syringe directly connected to the infusion cannula. (Right) Grafting using the Reverse Liposuction Technique along needle sticks in the inframammary crease.

\section{Post operative care}

In the first 24 hours post grafting there is no external compression or negative pressure used. Patients are placed in standard girdles as for routine liposuction. Beginning at 24-48 
hours after grafting, patients are placed into BRAVA domes, which are placed under low suction for a period of 14-21 days. The use if BRAVA in the postoperative period may act as a splint to protect the graft and may aid in volume maintenance by continued stimulation of the recipient site.

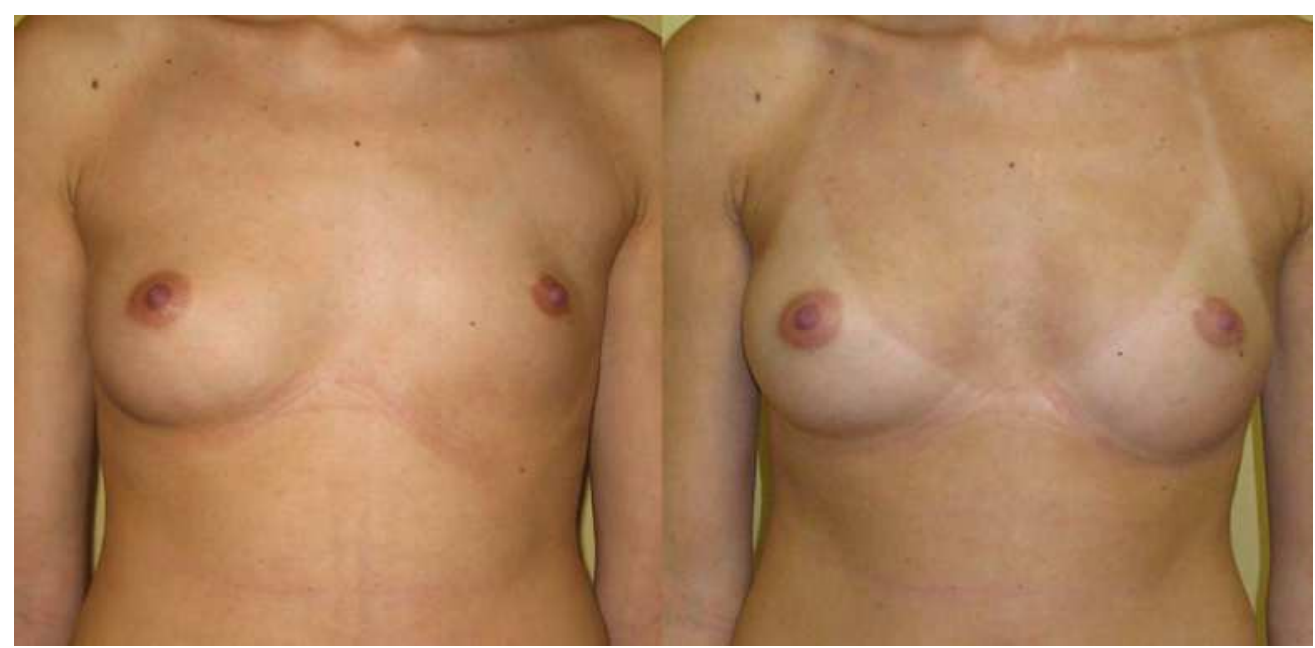

Fig. 11. Before (left) and after (right) reconstruction of the left breast. This patient received $300 \mathrm{cc}$ of transplanted fat. Her result is stable at 3 years postop.

\section{The emerging role of fat grafting in breast reconstruction}

Due to the wide availability of donor fat, ease of collection and minimal morbidity associated with liposuction, fat grafting has the potential to become a versatile tool in breast reconstruction. A review of the literature reveals there are a growing number of published reports on the use of fat grafting in breast reconstruction after surgery for breast cancer. While some of them are case reports (Del Vecchio 2009, Babovic 2010, Delay 2010, Panettiere 2011, Fitoussi 2009), a considerable number describe their experience with 40 or more patients (Spear 2005, Serra-Renom 2010, Sinna 2010, Rietjens 2011, Losken 2011, Missana 2007, Delay 2008, Panettiere 2009, Kanchwala 2009).

In 2005, Spear et al published one of the initial studies about the use of fat grafting in breast reconstruction. This study reported results of 37 small-volume cases (six patients bilateral) for small border zone cosmetic irregularities after reconstructive breast surgery ( 25 implant reconstructions, 17 transverse rectus abdominis muscle (TRAM) reconstructions, one TRAM and implant reconstruction). The average injected volume was relatively small $(116 \mathrm{ml})$ and these cases were not intended for reconstruction of core volume. The complication rate of $8.5 \%$ (cellulitis and oil cysts) at a mean follow up of 15 months is manageable, with $85 \%$ of patients realizing some satisfactory result.

Similar findings were reported by Missana et al in 2007 when they published their experience with small volume non-core fat grafting in 69 patients (74 injections) for revision of border zone defects following flap reconstruction or for defects following lumpectomy. 
The average volume injected was $67--77 \mathrm{ml}$ for breast conservation therapy and between 140-300 $\mathrm{ml}$ for implant and autologous flap reconstruction revisions. These cases must be distinguished from core volume reconstructions. In addition, they did not use pre-expansion and therefore these cases required multiple injection sessions. $86.5 \%$ of patients were deemed to have good or very good results. The rate of fat necrosis was $7.4 \%$

In addition to using fat simply as a filler, the regenerative work of Rigotti et al (2007) demonstrated a significant reversal in radiation damage after fat grafting in 20 patients. Fat, not acting simply as a filler, appeared to have a regenerative effect on the reversal of the radiation fibrosis and scarring. All the patients' LENT SOMA scores improved from 3-4 to 01. (LENT SOMA is a scale developed to have an objective assessment of post-radiation skin changes like degree of retraction or atrophy, edema, ulceration, telangiectasia, postradiation fibrosis, arm lymphedema, skin sensation and pigmentation change). The number of procedures ranged from 1-6 with most patients needing 2-3 procedures. The volume injected varied between $60-80 \mathrm{cc}$ in each injection. The mean follow up was 30 months and they reported no complications. This study used hyper concentrated fat for grafting and attributed the radiation damage reversal to the angiogenic potential of adipose derived stem cells (ADSC), which reside in natural fat.

Panettiere et al. reported similar improvement in radiation damage using fat grafting in 2009 (Panettiere et al, 2009). Their study population addressed 62 patients ( 20 active, 42 controls) who had undergone mastectomy, radiation and implant reconstruction. Fat grafting once again, was used as an ancillary technique to smooth border zone defects or to treat radiation damaged tissue. These patients did not undergo pre-expansion and had relatively tight, small-capacity recipient sites. The mean number of fat grafting sessions performed on each reconstructed breast was 3.4 with an average volume of $24.5 \mathrm{ml}$ of autologous fat injected in each session. LENT SOMA scores improved in all patients in the intervention group and capsular contractures were downgraded as well. They reported no complications.

Delay et al (2008) reported extremely high patient satisfaction scores after using fat grafting to treat the sequelae of breast conservation therapy (lumpectomy and radiation) in 42 patients. Delaporte et al (2009) used fat grafting to reconstruct mastectomy defects in 15 patients. Average volume injected was $600 \mathrm{ml}$ over 3 sessions. They reported good patient satisfaction scores as well.

The overwhelming theme in all of these studies is that small volume fat grafting for border zone defects and for radiation damage can be successfully performed in the absence of preexpansion, especially when fat is hyper-concentrated, small volumes (less than 100cc) are used, and fat is transplanted in serial sessions. This is distinctly different from mega volume fat grafting for core volume replacement, which we employ as a first-line treatment for breast reconstruction. Such findings support our previously stated contention that not all fat grafting is the same, and must be stratified along a matrix of volume and regenerative demands at the recipient site.

Despite the large number of patient series of breast reconstruction patients receiving small amounts of fat as a final touch for achieving better aesthetic outcomes, there are few reports of "core volume" breast reconstruction being done exclusively by fat grafting (Del Vecchio, 
2009, Babovic 2010, Delay et al 2010, Panettiere et al 2011, Fitoussi et al 2009). Because in all but one of these reports pre-expansion was not used and one begins with an absent breast mound or a thinned mastectomy skin flap, there are recipient site capacity issues in these cases and these operations often require more than 3 sessions.

\section{Controversies and future directions}

\subsection{Sequelae of fat transplantation and cancer surveillance}

As early as Lyndon Peer's work in fat grafting (Peer, 1950), it is a clinically accepted reality that not all that maintains volume following fat grafting represents viable adipocytes. Peer in fact stated his estimated $45 \%$ resorption rate was due to a combination of apoptosis and necrosis that subsequently lead to fibrosis, oil cysts and calcification. Legitimate concerns over these sequelae served as the cause for fat grafting's dismissal from the plastic surgery community through the ASPRS 1987 position paper on the subject. The paper stated:

"The committee is unanimous in deploring the use of autologous fat injection in breast augmentation. Much of the injected fat will not survive, and the known physiological response to necrosis of this tissue is scarring and calcification. As a result, detection of early breast carcinoma through xerography and mammography will become difficult and the presence of disease may go undiscovered."(ASPRS, 1987).

Breaking down the ASPRS statement into two parts, one can, in 2011, address each of them with a more evidence-based approach than was merely expert opinion in 1987:

We really still no not know how much of the injected fat survives, and there is no good accurate method to do so. Proponents of the scaffold theory do not believe any of the fat survives. In 2011, detection of early breast cancer can easily be distinguished from fat necrosis and oil cysts. In fact, the radiographic changes after fat grafting to the breast are no different than those after other conventional and well-accepted breast surgery (PierrefeuLagrange et al, 2006, Coleman and Saboeiro, 2007, Gosset et al, 2008, Zheng et al, 2008, Veber et al, 2011).

The answer to addressing radiographic sequelae of fat grafting, perhaps, lies in a riskadjusted approach to classifying radiographic findings after breast fat grafting (Del Vecchio, 2011). The ASPS revised their position on fat grafting and their new policy statement reads:

"Based on a limited number of studies with few cases, there appears to be no interference with breast cancer detection; however, more studies are needed to confirm these preliminary findings"' (Level IV, V evidence) (Gutowski, 2009)

\subsection{Neoplastic potential}

The role of adipose-derived stem cells (ADSC) in wound healing has been described (Kim et al, 2007) and may have clinical use in treating radiation injury to irradiated breast tissue. Although this has been attributed to the secretion of angiogenic factors by human adipose stromal cells (Rehman et al, 2004), the naked truth is we really do not currently have a clear mechanism of action for this clinical observation. Some bone marrow derived stem cells, when placed into animal cancer models, appear to accelerate the growth of the underlying 
cancer (Liu et al, 2011). This observation cannot however, be translated to the risk of natural fat and their inherent concentration of adipocyte derived stem cells initiating breast cancer.

Women have a 1 in 8 risk of being affected by breast cancer in their lifetime. There is no evidence to date that this incidence is any greater in women who have had fat injected into all or part of their breasts. Although proxies for long-term carcinogenic effects on fat grafting and breast cancer have been reported in patients following breast cancer treatment with or without subsequent fat grafting (Delay et al, 2009), these are not prospective studies of a normal population of women with or without fat transplantation over many years, which is what will be necessary to fully answer the carcinogenesis question. To date, there appears to be no increased risk but it is too early to draw any conclusions. Therefore, in 2011, the use of fat grafting to the breast for reconstruction or for augmentation should include a thorough discussion of the unknown risk of fat causing breast cancer, and this discussion should be made clear with the patient and be well documented in the medical record.

\section{Conclusion}

Fat grafting to the breast has rapidly evolved as a safe technique with a wide range of applications in breast reconstructive surgery. There is still a lack of standardization in the techniques used, but trends towards time management and simplification of technique are appearing. Standardization in mammography imaging and reading in the fat-grafted breast is expected to improve and ease concerns over calcifications and oil cysts being misread as cancer, reducing the risk of unnecessary biopsies.

At this point of time, its technically simpler and lower-risk indication is for contour correction in conjunction with other reconstructive operations. However, it can be exclusively used for breast reconstruction for core volume projection, obviating the need for an initial core volume strategy that eventually requires fat transplantation for correction in the majority of cases.

\section{References}

Aboudib JHC, Cardoso de Castro C, Gradel J. Hand rejuvenescence by fat filling. Ann Plast Surg 1992 Jun; 28: 559-64

ASPRS Ad-Hoc Committee on new Procedures: Report on Autologous fat transplantation. Plast Surg Nurs 1987 Winter; 7(4):140-141

Babovic S. Complete breast reconstruction with autologous fat graft - a case report. J Plast Reconstr Aesthet Surg. 2010 Jul; 63(7): 561-3

Baker, T. BRAVA Non-Surgical Breast Expansion. Presentation at the American Society of Aesthetic Plastic Surgeons Annual Meeting, Orlando, Florida. April, 2006

Bernard RW, Beran SJ. Autologous fat graft in nipple reconstruction.Plast Reconstr Surg. 2003 Sep 15; 112(4): 964-8

Billings E Jr, May JW. Historical review and present status of free fat graft autotransplantation in plastic and reconstructive surgery. Plast Reconstr Surg 1989 Feb; 83(2):368-381 
Bircoll M. Cosmetic breast augmentation utilizing autologous fat andliposuction techniques. Plast Reconstr Surg. 1987 Feb; 79(2): 267-71

Bircoll M, Novack BH. Autologous fat transplantation employing liposuction techniques. Ann Plast Surg. 1987 Apr; 18(4): 327-9

Cervelli V, Palla L, Pascali M, De Angelis B, Curcio BC, Gentile P. Autologous platelet-rich plasma mixed with purified fat graft in aesthetic plastic surgery. Aesthetic Plast Surg. 2009 Sep; 33(5): 716-21.

Chajchir A. Fat injection: long-term follow-up. Aesthetic Plast Surg 1996; 20: 291-6

Coleman, Sydney R. M.D.; Saboeiro, Alesia P. M.D. Fat Grafting to the Breast Revisted: Safety and Efficacy. Plast Reconstr Surg. 2007 Mar; 119(3): 775-85; discussion 786-7

Cronin T, Gerow F. Augmentation Mammaplasty: A new natural feel prosthesis. Transactions of the Third International Congress of Plastic Surgery, Amsterdam. Excerpta Medica Foundation. 1964; 41-49

Czerny V. DreiPlastischeOperationen.III. Plastischer Ersatz der Brustdrüsedurchein Lipom.Verhandlungen der DeutschenGesellscahftfürChirurgie 1895;II:216-217

De Cholnoky T. Late adverse results following breast reconstructions. Plast Reconstr Surg. 1963 May;31:445-52

Del Vecchio D. Breast reconstruction for breast asymmetry using recipient site preexpansion and autologous fat grafting: a case report. Ann Plast Surg. 2009 May; 62(5): 523-7

Del Vecchio DA. Discussion: Clinical analyses of clustered microcalcifications after autologous fat injection for breast augmentation. Plast Reconstr Surg. 2011

Apr; 127(4): 1674-6

Delay E, Gosset J, Toussoun G, Delaporte T, Delbaere M. [Efficacy of lipo-modelling for the management of sequelae of breast cancer conservative treatment]. Ann Chir Plast Esthet. 2008 Apr;53(2):153-68

Delay E, Garson S, Tousson G, Sinna R. Fat injection to the breast: technique, results, and indications based on 880 procedures over 10 years. Aesthetic Surg J.2009 SepOct;29(5):360-76

Delay E, Sinna R, Chekaroua K, Delaporte T, Garson S, Toussoun G. Lipomodelingof Poland's syndrome: a new treatment of the thoracic deformity. Aesthetic Plast Surg. 2010 Apr; 34(2): 218-25

Dolderer JH, Abberton KM, Thompson EW, Slavin JL, Stevens GW, Penington AJ, Morrison WA. Spontaneous large volume adipose tissue generation from avascularized pedicled fat flap inside a chamber space. Tissue Eng. 2007 Apr; 13 (4): 673-81

Erdim M, Tezel E, Numanoglu A, Sav A. The effects of the size of liposuctioncannula on adipocyte survival and the optimum temperature for fat graft storage: an experimental study. J Plast Reconstr Aesthet Surg. 2009 Sep; 62(9): 1210-4

Fitoussi A, Pollet AG, Couturaud B, Salmon RJ. Secondary breast reconstruction using exclusive lipofilling Ann Chir Plast Esthet. 2009 Aug; 54(4): 374-8

Goldwyn RM. Vincenz Czerny and the beginnings of breast reconstruction.Plast Reconstr Surg. 1978 May;61(5):673-81 
Gosset J, Guerin N, Toussoun G, Delaporte T, Delay E. Radiological evaluation after lipomodelling for correction of breast conservative treatment sequelae. Ann Chir Plast Esthet. 2008 Apr; 53(2): 178-89.

Gumucio CA, Pin P, Young VL, Destouet J, Monsees B, Eichling J: The effect of breast implants on the radiographic detection of microcalcification and soft-tissue masses. Plast Reconstr Surg 1989 Nov; 84(5): 772-8; discussion 779-82

Gutowski KA; ASPS Fat Graft Task Force. Current applications and safety ofautologous fat grafts: a report of the ASPS fat graft task force. Plast Reconstr Surg. 2009 Jul; 124(1): 272-80

Halsted WS. I. The Results of Operations for the Cure of Cancer of the Breast Performed at the Johns Hopkins Hospital from June 1889 to January 1894. Ann Surg. 1894 Nov; 20(5): 497-555

Halsted WS. I. The Results of Radical Operations for the Cure of Carcinoma of the Breast. Ann Surg. 1907 Jul; 46 (1): 1-19

Hang-Fu L, Marmolya G, Feiglin DH. Liposuction fat-fillant implant for breast augmentation and reconstruction. Aesthetic Plast Surg. 1995 Sep-Oct; 19(5): 427-37

Hartrampf CR, Scheflan M, Black PW. Breast reconstruction with a transverse abdominal island flap. Plast Reconstr Surg. 1982 Feb; 69(2): 216-25

Hyakusoku H, Ogawa R, Ono S, Ishii N, Hirakawa K. Complications after autologous fat injection to the breast. Plast Reconstr Surg. 2009 Jan; 123(1): 360-70

Illouz YG. Body contouring by lipolysis: a five-year experience with over 3000 cases. Plast Reconstr Surg 1983; 72(5): 591-597

Illouz YG, Sterodimas A. Autologous fat transplantation to the breast: a personal technique with 25 years of experience. Aesthetic Plast Surg. 2009 Sep; 33(5): 706-15

Kanchwala SK, Glatt BS, Conant EF, Bucky LP. Autologous fat grafting to the reconstructed breast: the management of acquired contour deformities. Plast Reconstr Surg. 2009 Aug; 124(2): 409-18

Kaufman MR, Bradley JP, Dickinson B, Heller JB, Wasson K, O'Hara C, Huang C,Gabbay J, Ghadjar K, Miller TA. Autologous fat transfer national consensus survey: trends in techniques for harvest, preparation, and application, and perception of short- and long-term results. Plast Reconstr Surg. 2007 Jan; 119(1):323-31

Khouri RK, Baker TJ. Initial experience with the BRAVA nonsurgical system of breast enhancement. Plast Reconstr Surg. 2002 Nov; 110(6):1593-1595.

Kim WS, Park BS, Sung JH, Yang JM, Park SB, Kwak SJ, Park JS. Wound healing effect of adipose-derived stem cells: a critical role of secretory factors onhuman dermal fibroblasts. J Dermatol Sci. 2007 Oct; 48(1):15-24

Kononas TC, Bucky LP, Hurley C, May JW, Jr.: The fate of suctioned and surgically removed fat after reimplantation for soft-tissue augmentation: a volumetric and histologic study in the rabbit. Plast Reconstr Surg 1993 Apr; 91(5): 763-768

Kurita M, Matsumoto D, Shigeura T, Sato K, Gonda K, Harii K, Yoshimura K. Influences of centrifugation on cells and tissues in liposuction aspirates: optimized centrifugation for lipotransfer and cell isolation. Plast Reconstr Surg 2008 Mar;121(3):1033-41; discussion 1042-3 
Lexer E. Fatty tissue transplantation. In: Die Transplantation, Part I. Stuttgart, Ferdinand Enke, 1919, pp. 265-302

Liu, S, Ginestier C, Sing, J et al. Breast Cancer Stem Cells Are Regulated by Mesenchymal Stem Cells through Cytokine Networks. Cancer Research 2011. 71(2); 614-24

Losken A, Jurkiewicz MJ. History of breast reconstruction. Breast Dis.2002;16:3-9

Losken A, Pinell XA, Sikoro K, Yezhelyev MV, Anderson E, Carlson GW.Autologous fat grafting in secondary breast reconstruction. Ann Plast Surg. 2011 May; 66(5):518-22

Manabe Y, Toda S, Miyazaki K, Sugihara H. Mature adipocytes, but not preadipocytes, promote the growth of breast carcinoma cells in collagen gel matrix culture through cancer-stromal cell interactions. J Pathol. 2003 Oct; 201 (2): 221-8

McCraw JB. The recent history of myocutaneous flaps. Clin Plast Surg. 1980 Jan; 7(1):3-7

Missana MC, Laurent I, Barreau L, Balleyguier C. Autologous fat transfer in reconstructive breast surgery: indications, technique and results. Eur J Surg Oncol. 2007 Aug; 33(6):685-90

Moseley, Timothy A. Ph.D.; Zhu, Min M.D.; Hedrick, Marc H. M.D. Adipose-Derived Stem and Progenitor Cells as Fillers in Plastic and Reconstructive Surgery. Plast Reconstr Surg: Volume 118(3S) Suppl1 September 2006 pp 121S-128S.

Neuber GA. Verhandlungen der Deutschen Gesellschaftfür Chirurgie 1893;1:66

Padoin AV, Braga-Silva J, Martins P, Rezende K, Rezende AR, Grechi B, Gehlen D, Machado DC. Sources of processed lipoaspirate cells: influence of donor site on cell concentration. Plast Reconstr Surg. 2008 Aug; 122(2):614-8

Panettiere P, Marchetti L, Accorsi D. The serial free fat transfer in irradiated prosthetic breast reconstructions. Aesthetic Plast Surg. 2009 Sep; 33(5):695-700

Panettiere P, Accorsi D, Marchetti L, Sgrò F, Sbarbati A. Large-Breast Reconstruction Using Fat Graft Only after Prosthetic Reconstruction Failure Aesthetic Plast Surg. 2011 Feb 27. [Epub ahead of print]

Peer LA. Loss of weight and volume in human fat grafts: With postulation of a "cell survival theory." Plast Reconstr Surg 1950; 5:217-230

Peer LA. Cell survival theory versus replacement theory. Plast Reconstr Surg 1955 Sep; 16(3): 161-8

Peer LA. The neglected free fat graft, its behavior and clinical use. Am J Surg. 1956 Jul; 92(1): 40-7

Pierrefeu-Lagrange AC, Delay E, Guerin N, Chekaroua K, Delaporte T.Radiological evaluation of breasts reconstructed with lipomodelling. Ann Chir Plast Esthet. 2006 Feb; 51(1):18-28

Pulagam SR, Poulton T, Mamounas EP. Long-term clinical and radiologic results with autologous fat transplantation for breast augmentation: case reports and review of the literature. Breast J. 2006 Jan-Feb; 12(1): 63-5

Radovan C. Breast reconstruction after mastectomy using the temporary expander.Plast Reconstr Surg. 1982 Feb; 69(2):195-208

Rehman J, Traktuev D, Li J, Merfeld-Clauss S, Temm-Grove CJ, Bovenkerk JE,Pell CL, Johnstone BH, Considine RV, March KL. Secretion of angiogenic and antiapoptotic factors by human adipose stromal cells. Circulation. 2004 Mar 16;109(10):1292-8 
Rietjens M, De Lorenzi F, Rossetto F, Brenelli F, Manconi A, Martella S, IntraM, Venturino M, Lohsiriwat V, Ahmed Y, Petit JY. Safety of fat grafting in secondary breast reconstruction after cancer. J Plast Reconstr Aesthet Surg. 2011 Apr; 64(4):477-83

Rigotti, Gino M.D.; Marchi, Alessandra M.D et al. Clinical Treatment of Radiotherapy Tissue Damage by Lipo-aspirate Transplant: A Healing Process Mediated by AdiposeDerived Adult Stem Cells. Plast Reconstr Surg. 2007 April 119(5): 1409-1422

Rigotti G, Marchi A, Battistoni A. Bioengineering of the mammary region with adipocyte derived stem cells: a new concept in expander implant breast reconstruction in patients affected by radiation side effects, local fat deficiencies and/or important skin changes. Presented at the European Association of Plastic Surgeons Annual Meeting, Gent, 2007

Saxena V, Hwang CW, Huang S, Eichbaum Q, Ingber D, Orgill DP. Vacuum-assisted closure: micro-deformations of wounds and cell proliferation. Plast Reconstr Surg 2004 Oct; 114(5):1086-96; discussion 1097-8

Saxena V, Orgill D, Kohane I. A set of genes previously implicated in the hypoxia response might be an important modulator in the rat ear tissue response to mechanical stretch. BMC Genomics 2007 Nov 23;8:430

Schneider WJ, Hill HL Jr, Brown RG. Latissimus dorsi myocutaneous flap for breast reconstruction. Br J Plast Surg. 1977 Oct;30(4):277-81

Serra-Renom JM, Muñoz-Olmo JL, Serra-Mestre JM. Fat grafting in postmastectomy breast reconstruction with expanders and prostheses in patients who have received radiotherapy: formation of new subcutaneous tissue. Plast Reconstr Surg. 2010 Jan; 125(1):12-8

Serra-Renom JM, Muñoz-Olmo J, Serra-Mestre JM.Breast reconstruction with fat grafting alone. Ann Plast Surg. 2011 Jun; 66(6):598-601

Shiffman MA, Mirrafati S. Fat transfer techniques: the effect of harvest and transfer methods on adipocyte viability and review of the literature. Dermatol Surg. 2001 Sep; 27(9):819-26

Sinna R, Delay E, Garson S, Delaporte T, Toussoun G. Breast fat grafting (lipomodelling) after extended latissimus dorsi flap breast reconstruction: a preliminary report of 200 consecutive cases. J Plast Reconstr Aesthet Surg. 2010 Nov; 63(11): 1769-77

Snyderman RK. Breast cancer and fat transplants. Plast Reconstr Surg. 1988 Jun; 81(6):991

Spear SL, Wilson HB, Lockwood MD. Fat injection to correct contour deformities in the reconstructed breast. Plast Reconstr Surg. 2005 Oct;116(5):1300-5

Ullmann Y, Shoshani O, Fodor A, Ramon Y, Carmi N, Eldor L, Gilhar A. Searching for the favorable donor site for fat injection: in vivo study using the nude mice model. Dermatol Surg. 2005 Oct; 31(10): 1304-7

Veber M, Tourasse C, Toussoun G, Moutran M, Mojallal A, Delay E. Radiographic findings after breast augmentation by autologous fat transfer. Plast Reconstr Surg. 2011 Mar; 127 (3): 1289-99

Zheng DN, Li QF, Lei H, Zheng SW, Xie YZ, Xu QH, Yun X, Pu LL: Autologous fat grafting to the breast for cosmetic enhancement: experience in 66 patients with long-term follow up; J Plast Reconstr Aesthet Surg. 2008 Jul; 61(7): 792-8. 
Zocchi ML, Zuliani F Bicompartmental breast lipostructuring. Aesthetic Plast Surg. 2008 Mar;32(2):313-28. 


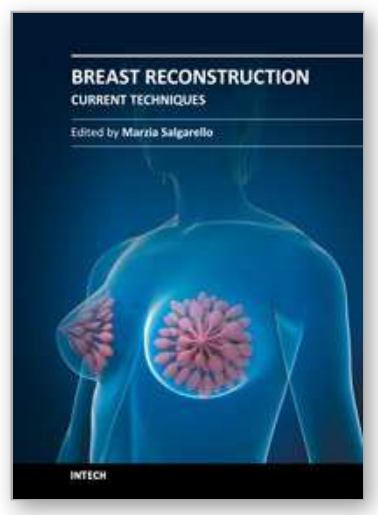

\author{
Breast Reconstruction - Current Techniques \\ Edited by Prof. Marzia Salgarello
}

ISBN 978-953-307-982-0

Hard cover, 276 pages

Publisher InTech

Published online 03, February, 2012

Published in print edition February, 2012

Breast reconstruction is a fascinating and complex field which combines reconstructive and aesthetic principles in the search for the best results possible. The goal of breast reconstruction is to restore the appearance of the breast and to improve a woman's psychological health after cancer treatment. Successful breast reconstruction requires a clear understanding of reconstructive operative techniques and a thorough knowledge of breast aesthetic principles. Edited by Marzia Salgarello, and including contributions from respected reconstructive breast plastic surgeons from around the world, this book focuses on the main current techniques in breast reconstruction and also gives some insight into specific topics. The text consists of five sections, of which the first focuses on the oncologic aspect of breast reconstruction. Section two covers prosthetic breast reconstruction, section three is dedicated to autogenous breast reconstruction, and section four analyzes breast reconstruction with a fat graft. Finally, section five covers the current approaches to breast reshaping after conservative treatment.

\title{
How to reference
}

In order to correctly reference this scholarly work, feel free to copy and paste the following:

Daniel Del Vecchio and Hetal Fichadia (2012). Autologous Fat Transplantation - A Paradigm Shift in Breast Reconstruction, Breast Reconstruction - Current Techniques, Prof. Marzia Salgarello (Ed.), ISBN: 978-953307-982-0, InTech, Available from: http://www.intechopen.com/books/breast-reconstruction-currenttechniques/autologous-fat-transplantation-a-paradigm-shift-in-breast-reconstruction

\section{INTECH}

open science | open minds

\section{InTech Europe}

University Campus STeP Ri

Slavka Krautzeka 83/A

51000 Rijeka, Croatia

Phone: +385 (51) 770447

Fax: +385 (51) 686166

www.intechopen.com

\section{InTech China}

Unit 405, Office Block, Hotel Equatorial Shanghai

No.65, Yan An Road (West), Shanghai, 200040, China

中国上海市延安西路65号上海国际贵都大饭店办公楼405单元

Phone: +86-21-62489820

Fax: $+86-21-62489821$ 
(C) 2012 The Author(s). Licensee IntechOpen. This is an open access article distributed under the terms of the Creative Commons Attribution 3.0 License, which permits unrestricted use, distribution, and reproduction in any medium, provided the original work is properly cited. 